\title{
Global Cooperative Signaling System for Automatic Train Protection
}

\author{
Wanting Zhao ${ }^{1+}$, Xiangxian Chen ${ }^{1}$, Zhujun Ling ${ }^{2}$, Zhenpeng $\mathrm{Nie}^{2}$, Wenbing Tang ${ }^{2}$, Guodong \\ Teng $^{2}$ and Lanqing $\mathrm{Hu}^{2}$ \\ ${ }^{1}$ Department of Instrumentation Science and Engineering, Zhejiang University, Hangzhou, China \\ ${ }^{2}$ Research and Development Center, Zhejiang United Science and Technology Co., Ltd, Hangzhou, China
}

\begin{abstract}
Rail transit signaling system is a fail-safe system. It is the most important part of train operation control. With the rapid development of urban rail transit in China, people have more and more requirements for train operation. The traditional Communication-based Train Operation Control (CBTC) system adopts the adhesion and closed system architecture and autonomous safety model, and it cannot meet the needs of more and more complex status of train operation such as fire disaster, flood, stuff dropped and so on. The new generation of global cooperative system for automatic train protection increases the equipment and interface for data acquisition and processing which can dispose the exogenous emergency events and complex status of train operation. Therefore, during the operating, the train can take the automatic protection measures, improving the safety and reliability of train operation, achieving the final principle of rail transit system: failsafe.
\end{abstract}

Keywords: global cooperative, automatic train protection, supervision, fail-safe.

\section{Introduction}

For the past few years, with the rapid development of Chinese economy and urbanization, urban rail transit has also entered the rapid developing period [1]. Along with the rapid development of urban rail transit, the status of train operation becomes more and more complicated. Since the traditional CBTC system uses the safety autonomous technology and adhesion framework, so it has no response to the exogenous emergency events or disposes it not in time. Therefore, the traditional CBTC system cannot meet more and more complex needs of today's urban rail transit. The traditional CBTC system only has response to the operation speed, train position, adjacent train's relation and other simple input states. It lacks data acquisition units and information interfaces which can respond the exogenous emergency events such as the temperature sensor and smoke detector for fire detection, infrared detection device for detecting foreign material dropped off the rail and so on. These defections bring unstable factors to the train operation and it reduces operation efficiency.

When traditional CBTC system has trouble with system or equipment faults such as train body structure fault, traction power supply system fault, and shield gate fault and so on, or when it faces the emergency situation and unpredictable faults during the train operation, usually, the system would change the mode to the manual operation. Due to the traditional CBTC system depends too much on the manual emergency processing when it meets the emergency situation, once the manual emergency processing goes wrong, and the train's safety and stable operation cannot be guaranteed, so the accident can happened easily. For example, on March 20, 2003, three automatic lock pull hook fault caused an outage of the entire lines for more than an hour in Shanghai metro line. In April 4, 2002, Shanghai metro line shutdown half an hour because of mechanical fault in opening the door [2].

+ Corresponding author. Tel.: + 8617816858876 .

E-mail address: wtzhao@zju.edu.cn 
Based on the traditional CBTC system, the new generation of global cooperative system for automatic train protection increases the equipment and interface for data acquisition and processing to ensure the train can monitor the state of the train body and rail line in real-time during the train operation process, so when the train meets the emergency situation during operation, it can take an automatic protection immediately. Therefore, the train can operate in a more safety, stable way.

\section{System Architecture}

Urban rail transit signaling system usually includes two parts: interlocking device and Automatic Train Control (ATC) system. And ATC system includes Automatic Train Protection (ATP) system, Automatic Train Operation (ATO) system and Automatic Train Supervision (ATS) system [3]. The main function of ATC system is realizing by the three parts: control center, central station signaling equipment room and carborne system. Combined with the corresponding ground supporting system, ATP, ATO and ATS system constitute the ATC close-loop system. Through the information transmission between the carborne ATP subsystem and the ground equipment, ATP subsystem realizing its main functions: train safety position interval, overspeed protection and train door control. So it can ensure the safety of train operation. The main functions of ATO subsystem are section train automatic operation, train speed adjustment and automatic spotting. And it can accept the operation scheduling instruction from the control center, and realizing the automatic adjustment of train operation. And ATS subsystem main function is supervising the status of train operation by the software to achieve the automatic management of networking, communication and operation. Among these, ATP subsystem takes the important function which ensures the safety of train operation in urban rail transit system, and it is also the most important part of ATC system. For the ATP subsystem, safety and reliability should be put in the first place.

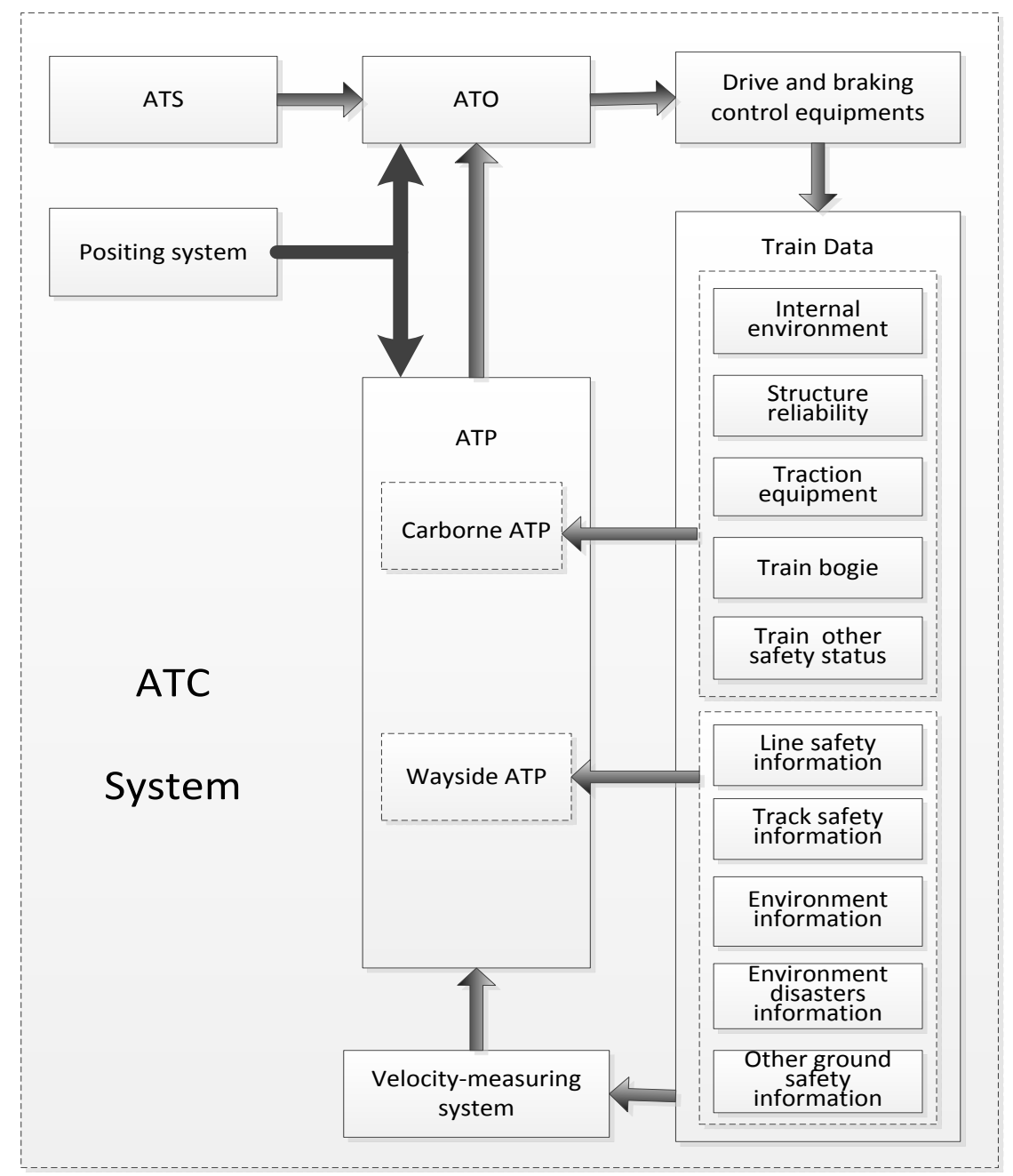

Fig. 1: Global cooperative signaling system for automatic train protection frame. 
ATP subsystem is a safety system, and its system design must conform to the principle of fail-safe. ATP subsystem is divided into carborne ATP subsystem and wayside ATP by IEEE 1474 standard. And carborne ATP subsystem, ATO subsystem and Train Operation Display (TOD) system compose the Carborne Control (CC) system. Wayside ATP subsystem is also called Zone Controller (ZC) system [4]. Based on the traditional CBTC system, the new generation of global cooperative signaling system for automatic train protection increases the equipment and interface which can collect and transmit the real-time data and detect status for train's external environment and inside status. Through real-time data acquisition and analysis of train structure, traction power supply system, line status and other system's situation, the train can supervise the train body and line's status in real-time during the operation. Therefore, the train can make a timely and appropriate response to the emergency events. And it improves the safety and reliability of train operation, realizing the principle of the rail transit system: fail-safe.

\subsection{Carborne ATP Subsystem}

The main function of the carborne ATP system is guarantee safe speed and safe position of the train. In addition, it includes the version of database's uploading, upgrade and error calibration, train control mode management, mobile license management, speed range curve calculation, train control and $\mathrm{CC}$ safety supervision.

The new generation carborne ATP subsystem of the global cooperative signaling automatic train protection system is equipped with speed sensor and radar velocity measurement, bringing out the function of the train safety measurement. The speed detection is mainly about speed sensor information which is installed on wheels, and train wheel in the operation process will be accompanied with problems like acceleration, deceleration idling and slipping. The new generation of carborne ATP subsystem considering the most unfavorable factors such as idling and slipping, makes up for the original velocity information, therefore it can calculate the safe speed per cycle. The ATP subsystem installs two speed sensors on each CC system, the speed sensors are the hot standby redundancy relation. If one of the speed sensors failed, the other one will adopt speed sensor information. If the two velocity sensors failed at the same time, then it will be determined as the speed fault, and CC will implement the emergency brake immediately. In the global cooperative signaling of carborne ATP subsystem, in light of the expansion of the fault detection equipment, the speed curve calculation requirements will be more systematic. In the calculation of the speed curve, the calculation of the target point braking curve and the target speed limit curve depends on the data collected by the fault detection equipment, in which the fault point will affect the calculation of the target point braking curve, and the target speed limit can be determined by the specific fault type. Specific fail-safe type and response reference is in Table 1 and Table 2.

\subsection{Wayside ATP Subsystem}

Wayside ATP subsystem is also called Zone Controller (ZC). According to the ground dynamic information, wayside ATP subsystem analysis the logic files which provided by application logic system, read the station equipment data provided by safe computer platform, then computes interlocking logic operation, and combine with the dispatching command information which given by the rail line status data, finally, putting out the related data by the safe computer platform. Using these data, the safe computer platform can build a real-time train operation license, and transfer it to the carborne ATP subsystem by the wireless communication system. Therefore, the system realizes moving block.

\section{Train Operation Fault Analysis}

For the fault analysis of train operation, it should start from the source. Finding the faulty source of the train operation, then collecting and analyzing the data of the faulty source, which focus on the different types and specific operative environment, finally determining the mode to response every single fault. The fault sources in the train operation can be broadly divided into the carborne fault source and the wayside fault source. The carborne fault source can be divided into the fault as train structure, traction power supply system and station staff system. Wayside fault source can be broadly divided into rail line fault, natural disaster and fire control fault. The following charts are for some specific fail-safe measures: 
Table 1. Rail Line Fail-Safe Measure

\begin{tabular}{|c|c|c|c|c|c|}
\hline Faulty unit & Faulty content & $\begin{array}{c}\text { Train control } \\
\text { system response }\end{array}$ & $\begin{array}{l}\text { Carborne ATP } \\
\text { response }\end{array}$ & $\begin{array}{l}\text { Wayside ATP } \\
\text { response }\end{array}$ & ATS response \\
\hline \multirow{4}{*}{ Rail } & High-low/level/gauge/direction & Limit speed & Limit speed & N/A & Advance alarm \\
\hline & $\begin{array}{l}\text { Rail crake/over loss/rail temperature } \\
\text { anomaly }\end{array}$ & Limit speed & Limit speed & N/A & Advance alarm \\
\hline & Rail fracture & Detained/EB & EB & detained & $\begin{array}{l}\text { Sound-light } \\
\text { alarm }\end{array}$ \\
\hline & Sudden heating of rail temperature & Detained/EB & EB & detained & $\begin{array}{l}\text { Sound-light } \\
\text { alarm }\end{array}$ \\
\hline \multirow[b]{2}{*}{ Turnout } & Guardrail/wing rail fault & Limit speed & Limit speed & N/A & Advance alarm \\
\hline & Frog fault & Detained/EB & EB & detained & $\begin{array}{l}\text { Sound-light } \\
\text { alarm }\end{array}$ \\
\hline \multirow[b]{2}{*}{ Subgrade } & Rain erosion & Limit speed & Limit speed & N/A & Advance alarm \\
\hline & Subside/landside & Detained/EB & EB & detained & $\begin{array}{l}\text { Sound-light } \\
\text { alarm }\end{array}$ \\
\hline \multirow{5}{*}{ Line bound } & Communication cable drop off & Detained/EB & EB & detained & $\begin{array}{l}\text { Sound-light } \\
\text { alarm }\end{array}$ \\
\hline & Catenary drop off & Detained/EB & EB & detained & $\begin{array}{l}\text { Sound-light } \\
\text { alarm }\end{array}$ \\
\hline & Abnormal stuff fall into rail & Detained/EB & EB & detained & $\begin{array}{l}\text { Sound-light } \\
\text { alarm }\end{array}$ \\
\hline & Staff fall into rail & Detained/EB & EB & detained & $\begin{array}{l}\text { Sound-light } \\
\text { alarm }\end{array}$ \\
\hline & $\begin{array}{c}\text { Protective net damaged/base station } \\
\text { beyond limit }\end{array}$ & Limit speed & Limit speed & detained & Advance alarm \\
\hline
\end{tabular}

Table 2. Natural Disaster Fail-safe Measure

\begin{tabular}{|c|c|c|c|c|}
\hline Faulty unit & $\begin{array}{c}\text { Train control system } \\
\text { response }\end{array}$ & $\begin{array}{l}\text { Carborne ATP } \\
\text { response }\end{array}$ & Wayside ATP response & ATS response \\
\hline Earthquake & EB/detained & EB & Detained & Sound-light alarm \\
\hline Flood & Limit speed/EB/detained & Limit speed or EB & Detained & $\begin{array}{l}\text { Advance alarm or } \\
\text { sound-light alarm }\end{array}$ \\
\hline Strong wind & Limit speed/EB/detained & Limit speed or EB & Detained & $\begin{array}{l}\text { Advance alarm or } \\
\text { sound-light alarm }\end{array}$ \\
\hline Rainstorm & Limit speed/EB/detained & Limit speed or EB & Detained & $\begin{array}{l}\text { Advance alarm or } \\
\text { sound-light alarm }\end{array}$ \\
\hline Landslide/debris flow & EB/detained & EB & Detained & Sound-light alarm \\
\hline
\end{tabular}

\section{Fail-Safe Test Case}

Fail-safe principle is the basic requirement to guarantee the safety of train operation. Even if a fault occurs during train operation, the system must ensure the safety of the train operation. Therefore, the key to ensure the safety of train operation is ensure the train control system can certainly execute fail-safe principle. Fail-safe principle is throughout the design of the global cooperative signaling system of train control. And it uses the simulation test system to simulate the possible fault conditions to verify the reliability and safety of the system's fail-safe.

\section{1. fault Response Mode}

The new generation of the global cooperative signaling train control system's fault response mode including the ATS system sound-light alarm and advance alarm, emergency brake through the CC system, speed limitation, protection of detaining the train by the wayside ATP.

\subsubsection{Carborne fail-safe}

If the system detects the fault information, the fault information message should be sent to CC and ATS.

1) The train system sends the train structure fault message to $\mathrm{CC}$ per period.

- If the protection mode is EB, the CC will imply EB immediately.

- If the protection mode is speed limitation, CC should set the $25 \mathrm{~km} / \mathrm{h}$ speed limitation immediately.

- If the protection mode is detainment, skip-stop, warning, advance alarm, and CC should take no protective measures.

2) Train fault system sends the train structure fault message to the ATS per period.

- If the protection mode is EB or speed limitation, then ATS will take no protective measures 
- If the protection mode is detainment, then ATS should send the detaining command to the train.

- If the protection mode is skip-stop, then ATS should send skip-stop command to the train.

- If the protection mode is warning, then ATS should imply sound-light alarm.

- If the protection mode is advance alarm, then ATS should imply the advance alarm.

\subsubsection{Wayside fail-safe}

If the system detects the fault information, the fault information message will be sent to ZC and ATS

1) The train system sends the train structure fault message to $\mathrm{ZC}$ per period.

- If the protection mode is $\mathrm{EB}$, then ZC will take the following measures: Send EB command to the section, then list section as a fault zone, MAL cannot enter the area.

- If the protection mode is speed limitation, then ZC will send the speed limitation command to the section of the list within the scope of the train immediately, when the $\mathrm{CC}$ receives the command, it will post a $25 \mathrm{~km} / \mathrm{h}$ speed limitation immediately.

- If the protection mode is detainment, skip-stop, warning, advance alarm, ZC will take no protective measures.

2) Train fault system sends the train structure fault message to ATS per period.

- If the protection mode is EB or speed limitation, then ATS will take no protective measures

- If the protection mode is detainment, then ATS will send detaining command to the train within the list area scope.

- If the protection mode is skip-stop, then ATS will send skip-stop to the train within the list area scope.

- If the protection mode is warning, the ATS will imply sound-light alarm.

- If the protection mode is advance alarm, then ATS will imply the advance alarm.

\section{Summary}

The new generation of global cooperative signaling for automatic train protection makes a breakthrough of partial safety control mode of the traditional CBTC system. The new system increases the real-time data acquisition and detection to supervise the external environment and the train inside state, so when the faults happened, such as train body structure fault, fault of traction power supply system, fire, flooding, staff drop down the rail and other emergency events which can have an adverse effect on train operation and personal property security, the train can make an appropriate response in time, avoiding serious accidents occurs. And it ensured the safety, stable and reliability of train operation, realizing the principle of rail transit system: fail safe.

\section{Acknowledgements}

This work is supported by the funding from the National Science and Technology Infrastructure Program of China under Grant 2015BAG19B03

\section{References}

[1] Pan-feng Liu, Xi-xi Qiu, Xiang-xian Chen. Urban Rail Transit Train Automatic Protection Operation System Software Design[J].Computer Engineering.2012,38(19): 1-5

[2] Shu-feng Shi, Sheng Yang, Li-tong Sun, Urban Rail Transit Safety-management Issues [J]. Urban Rail Transit, 2003, (2): 26 2

[3] Xiao-qing Zeng, Chang-lin Wang, Shu-jing Zhang. Communication-based Train Operation Control for Rail Transit [M]. Shanghai: Tongji University Press, 2007. 12-22

[4] IEEE.1474.1-2004 - IEEE Standard for Communications-Based Train Control (CBTC) Performance and Functional Requirements[S].USA:IEEE,200

[5] Rail Transit Vehicle Interface Standards Committee of the IEEE Vehicular Society. IEEE Standard for Communications-Based Train Control(CBTC ) Performance and Functional Requirements [M]. New York: IEEE Publisher, 1999: 5-8 